\title{
PROFIL KANDIDIASIS KUTIS DI POLIKLINIK KULIT DAN KELAMIN RSUP PROF. DR. R.D. KANDOU MANADO PERIODE 2009-2011
}

\author{
${ }^{1}$ Rara Safira Seru \\ ${ }^{2}$ Pieter Levinus Suling \\ ${ }^{2}$ Herry E.J. Pandeleke
}

\author{
${ }^{1}$ Kandidat Skripsi Fakultas Kedokteran Universitas Sam Ratulangi \\ ${ }^{2}$ Bagian Ilmu Kesehatan Kulit dan Kelamin Fakultas Kedokteran \\ Universitas Sam Ratulangi Manado \\ Email:good_kratoz@yahoo.com
}

\begin{abstract}
Candidiasis is a diverse group of infections caused by Candida albicans. Superficial skin infections are one of the forms of cutaneous candidiasis infection. The purpose of this research is to evaluate the patient's profile of cutaneous candidiasis in the Dermatovenereology clinic of Prof. Dr. R. D. Kandou Hospital Manado in 2009-2011. This research was perform retrospectively to patients with cases of cutaneous candidiasis who came to Dermatovenereology clinic in 2009-2011. Data regarding number of patients, types of cutaneous candidiasis, sex, and age were recorded from medical record. The study showed that of a total of 10,003 visits in the years 2009-2011 there were $160(0.53 \%)$ new cases of cutaneous candidiasis, $26.27 \%$ of the 598 new cases of fungal disease, the type of intertriginous candidiasis is the highest (95.63\%), most often women who suffer from cutaneous candidiasis (61.25\%), mostly in the $45-64$ age group (38.13\%). It can be conclude that cutaneous candidiasis is quite often found in the department of Prof. Dr. R. D. Kandou Manado.
\end{abstract}

Keywords: cutaneous candidiasis, dermatomycoses.

\begin{abstract}
Abstrak: Kandidiasis adalah berbagai kelompok infeksi yang disebabkan oleh Candida albicans dan spesies lain dalam genus Candida. Infeksi kulit superficial merupakan salah satu bentuk infeksi dari kandidiasis kutis. Tujuan dari penelitian ini untuk mengetahui profil kandidiasis kutis pada poliklinik Kulit dan Kelamin RSUP Prof Dr R. D. Kandou Manado pada tahun 2009-2011. Penelitian ini dilakukan secara retrospektif pada pasien dengan kandidiasis kutis yang datang ke poliklinik Kulit dan Kelamin pada tahun 2009-2011. Dilakukan pencatatan data dari catatan medik mengenai jumlah pasien, jenis kandidiasis kutis, jenis kelamin dan umur. Hasil yang didapatkan menunjukkan bahwa dari total 10003 kunjungan pada tahun 2009-2011 terdapat 160 orang (0,53\%) penderita baru kandidiasis kutis, 26,27\% dari 598 kasus baru penyakit jamur, dengan jenis kandidiasis tertinggi ialah kandidiasis intertriginosa (95,63\%), perempuan yang paling sering menderita kandidiasis kutis (61,25\%), paling banyak pada kelompok umur 45-64 (38,13\%). Dapat simpulkan bahwa kandidiasis kutis cukup sering didapatkan di RSUP Prof Dr. R. D. Kandou Manado.
\end{abstract}

Kata kunci: dermatomikosis, kandidiasis kutis.

Kandidiasis merupakan berbagai kelompok infeksi yang disebabkan oleh Candida albicans ataupun spesies lain dari genus
Candida. Organisme ini khususnya menginfeksi kulit, kuku, membran mukosa, dan traktus gastrointestinal, tetapi organisme ini 
juga dapat menyebabkan penyakit sistemik. ${ }^{1}$

Infeksi kulit superfisial adalah salah satu bentuk infeksi dari kandidiasis kutaneous. $^{2}$ Saat ini kasus kandidiasis kutis masih sering dijumpai. ${ }^{3}$ Di Indonesia, kandidiasis kutis menepati urutan ketiga dalam insidensi dermato-mikosis. Tetapi pada beberapa kota, yaitu Makassar, Medan, dan Denpasar, kandi-diasis kutis menempati urutan pertama dalam insidensi dermatomikosis. ${ }^{4}$

Gambaran klinik dari kandidiasis kutis tergantung dari lokasi infeksinya; intertriginosa, generalisata, paronikia dan onikomikosis, diaper rash, granuloma kandida. ${ }^{5,6}$ Penelitian yang dilakukan oleh Berhimpon mengenai mikosis superfisialis di Poliklinik Kulit dan Kelamin RSUP Prof Dr R. D. Kandou Manado periode 1999-2001 kandidiasis intertriginosa menempati urutan pertama $(76,80 \%)$ dari semua jenis kandidiasis sedangkan, onikomikosis dan paronikia hanya didapati pada 68 penderita $(0,48 \%){ }^{7}$

Kandidiasis merupakan penyakit yang dapat terdapat di seluruh dunia, dapat menyerang laki-laki maupun perempuan, dan semua golongan umur terutama bayi dan orang tua. ${ }^{6}$

Tujuan penelitian ini ialah untuk mengetahui profil kandidiasis kutis pada Poliklinik Kulit dan Kelamin RSUP Pıu Dr R. D. Kandou Manado pada tahun 2009-2011.

\section{METODE PENELITIAN}

Penelitian ini dilakukan secara retrospektif dengan melihat catatan medik pasien kandidiasis kutis yang datang berobat ke Poliklinik Kulit dan Kelamin RSUP Prof. Dr. R.D. Kandou Manado periode 2009-2011. Dilakukan pencatatan data mengenai jumlah kasus, jenis kandidiasis kutis, jenis kelamin, dan umur. Jenis kandidiasis kutis yang dipakai berdasarkan pembagian Rippon; kandidiasis intertriginosa, kandidiasis generalisata, paronikia dan onikomikosis, dan granuloma kandida, ditambah kandidiasis intertriginosa dan paronikia.

\section{HASIL PENELITIAN}

Hasil penelitian yang didapatkan selama penelitian, jumlah kasus baru kandidiasis kutis yaitu sebanyak 160 kasus dari 10003 kunjungan yang ada di poliklinik Kulit dan Kelamin RSUP Prof. Dr. R.D. Kandou Manado dalam 20092011, dengan rerata 0,53\% kasus pertahun. Pada divisi mikologi kandidiasis kutis memiliki persentasi sebesar $26,27 \%$ dalam kasus baru dermatomikosis.

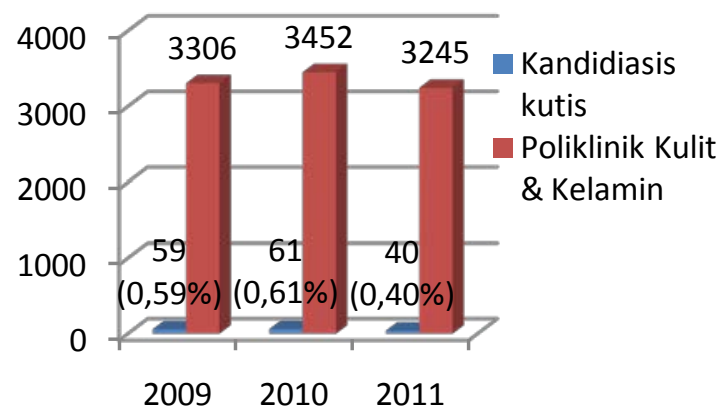

Gambar 1. Perbandingan Kasus Baru Kandidiasis Kutis dengan Kunjungan di Poliklinik Kulit dan Kelamin RSUP Prof. Dr. R.D. Kandou Manado Periode 2009-2011

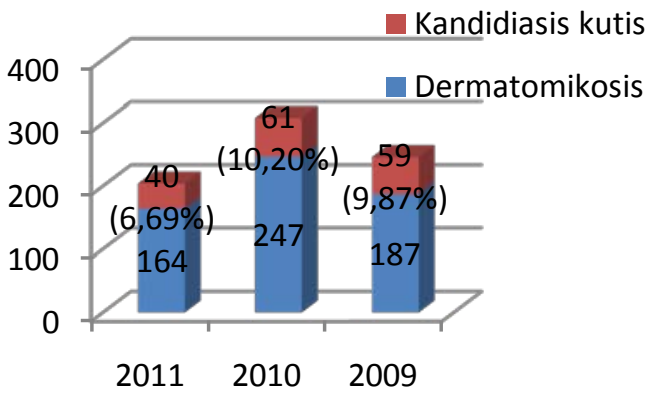

Gambar 2. Perbandingan Kasus Baru Kandididasis Kutis dengan Kasus Baru Dermatomikosis di Divisi Mikologi Poliklinik Kulit dan Kelamin RSUP Prof. Dr. R.D. Kandou Manado Periode 2009-2011. 
Jenis kandidiasis kutis yang paling sering dijumpai yaitu kandidiasis intertriginosa dengan jumlah 153 kasus (95,63\%), diikuti oleh paronikia dan onikomikosis sebanyak 6 kasus (3,75\%).

Perempuan lebih sering menderita kandidiasis kutis dibandingkan laki-laki. Kelompok umur yang paling banyak menderita kandidiasis kutis adalah kelompok umur 45-64 tahun dan yang paling sedikit menderita kandidiasis kutis ialah kelompok umur $<1$ tahun.

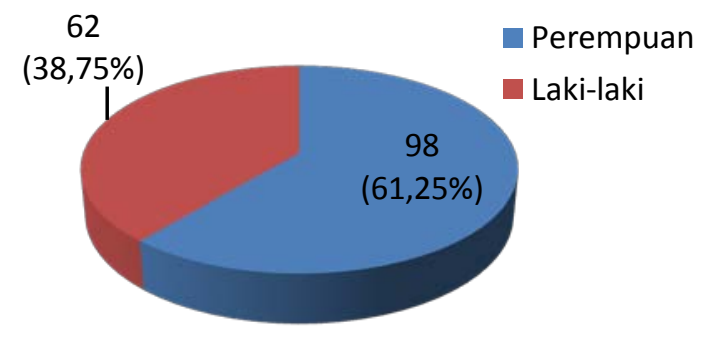

Gambar 3. Distribusi Jenis Kelamin Kasus Baru Kandidiasis Kutis di Poliklinik Kulit dan Kelamin RSUP Prof. Dr. R.D. Kandou Manado Periode 2009-2011.

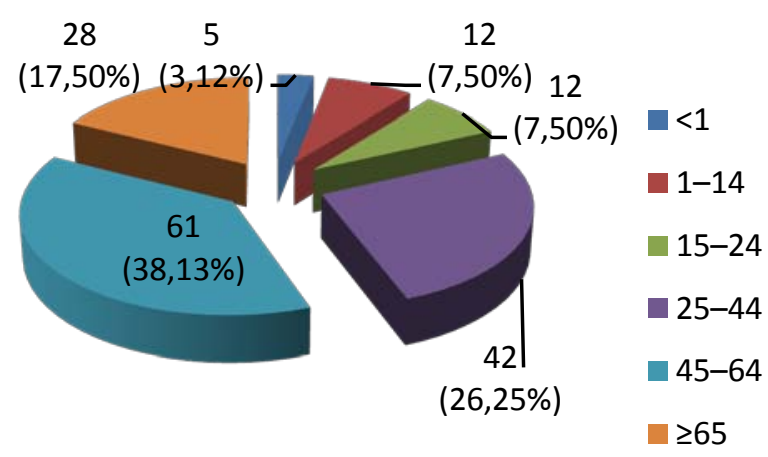

Gambar 4. Distribusi Kelompok Umur Kasus Baru Kandidiasis Kutis di Poliklinik Kulit dan Kelamin RSUP Prof. Dr. R.D. Kandou Manado Periode 2009-2011.

Tabel 1. Distribusi Jenis Kandidiasis Kutis di Poliklinik Kulit dan Kelamin RSUP Prof. Dr. R.D. Kandou Manado Periode 2009-2011

\begin{tabular}{|c|c|c|c|c|c|}
\hline \multirow{2}{*}{ Jenis Kandidiasis Kutis } & \multicolumn{3}{|c|}{ Tahun } & \multirow{2}{*}{ Total } & \multirow{2}{*}{$\%$} \\
\hline & 2009 & 2010 & 2011 & & \\
\hline Intertriginosa & 58 & 57 & 38 & 153 & 95,63 \\
\hline Generalisata & 0 & 0 & 0 & 0 & 0 \\
\hline $\begin{array}{l}\text { Onikomikosis dan } \\
\text { Paronikia }\end{array}$ & 1 & 3 & 2 & 6 & 3,75 \\
\hline Gramuloma Kandida & 0 & 0 & 0 & 0 & 0 \\
\hline $\begin{array}{l}\text { Intertriginosa dan } \\
\text { Paronikia }\end{array}$ & 0 & 1 & 0 & 1 & 0,62 \\
\hline Total & 59 & 61 & 40 & 160 & 100 \\
\hline
\end{tabular}




\section{BAHASAN}

Kasus baru kandidiasis kutis yaitu sebanyak 160 kasus dari 10003 kunjungan yang ada di poliklinik Kulit dan Kelamin RSUP Prof. Dr. R.D. Kandou Manado dalam 2009-2011. Adanya penurunan dalam jumlah kunjungan pada tahun terakhir dapat disebabkan oleh karena tingkat kesadaran yang cukup tinggi dalam masyarakat untuk mencegah penyakit kulit dengan menghindari faktor-faktor predisposisi yang mungkin diperoleh, juga dapat dikarenakan penderita tidak lagi berobat ke rumah sakit tetapi ke praktek dokter ataupun klinik-klinik kulit yang ada. Fasilitas pelayanan kesehatan yang mungkin dirasakan kurang memadai dan kemungkinan biaya yang dikeluarkan juga tidak sedikit menjadi salah satu faktor penurunan kunjungan pasien ke rumah sakit.

Pada data distribusi penyakit jamur, kandidiasis kutis memiliki persentasi sebesar 26,27\% dari keseluruhan kasus baru dermatomikosis. Penelitan yang dilakukan oleh Citrashanty dan Suyoso di Divisi Mikologi URJ Penyakit Kulit dan Kelamin RSU Dr. Soetomo Surabaya tahun 2008-2010 juga pada penelitian Nawal, Patel, Patel, Soni, dan Khandelwal mengenai mikosis superfisial di India, infeksi kandida tidak pada posisi pertama dalam kasus penyakit jamur. ${ }^{8,9}$ Penelitian yang dilakukan oleh Havlickova, Czaika, Friedrich mengenai epidemiologi mikosis pada kulit di seluruh dunia, untuk Asia hanya pada penelitian di Cina yang mendapati Candida spp dan berada pada posisi ketiga (14\%). ${ }^{10}$ Secara umum jika melihat data epidemiologi yang ada infeksi Candida tidak terlalu banyak jika dibandingkan dengan penyakit jamur lainnya. Faktor predisposisi kandidiasis mungkin semakin dikenal oleh masyarakat, sehingga kasus tersebut bukanlah yang paling sering ditemukan.

Berdasarkan data distribusi klasifikasi kandidiasis kutis, jenis kandidiasis kutis yang paling banyak ditemukan ialah kandidiasis intertriginosa, diikuti onikomikosis dan paronikia. Penelitian yang dilakukan oleh Berhimpon mendapatkan hasil yang sama, kandidiasis intertriginosa merupakan jenis kandidiasis yang paling banyak ditemukan. ${ }^{6}$ Jamur kandida memiliki predileksi pada pada tempat yang lembab serta lipatan kulit yang mengalami maserasi; lipatan kulit merupakan tempat yang paling sering mengalami kandidiasis. ${ }^{11}$ Iklim tropis Indonesia dapat menjadi penyebab, keadaan yang panas membuat tubuh berkeringat dan menjadi lembab.

Kandidiasis kutis lebih banyak ditemukan pada perempuan dibanding lakilaki (tabel 4). Hasil yang sama juga diperoleh pada penelitian Berhimpon (60,61\%) dengan jumlah perempuan lebih banyak dibanding laki-laki. ${ }^{7}$ Hal ini dapat terjadi karena perempuan melakukan pekerjaan rumah tangga yang banyak kontak dengan air, kehamilan, dan pemakaian pakaian yang ketat sehingga menyebabkan keringat dan lembab. ${ }^{7}$ Hal lain yang kemungkinan berpengaruh pada hasil ini ialah populasi perempuan lebih banyak dibandingkan dengan laki-laki atau lesi pada kandidiasis mengakibatkan rasa tidak nyaman, biasanya perempuan lebih memperhatikan penampilan, memilih untuk memeriksakan diri ke rumah sakit.

Kelompok umur yang paling banyak menderita kandidiasis kutis, berdasarkan data, ialah kelompok umur 45-64 tahun (38,13\%). Hal ini mungkin dikarenakan oleh batasan umur yang luas pada kelompok umur 45-64 tahun, dan juga dengan semakin bertambahnya usia, terdapat hubungan dengan peningkatan masalah kesehatan yang kronis, seperti diabetes, dan sirkulasi perifer yang buruk. ${ }^{12}$ Usia 45 tahun keatas merupakan salah satu faktor resiko yang tidak dapat dirubah pada diabetes mellitus. ${ }^{13}$ Imunitas pada orang tua telah menurun sehingga memudahkan untuk terjadinya infeksi. Kelompok yang paling jarang menderita kandidiasis kutis merupakan kelompok umur $<1$ tahun (3,31\%) yang biasanya memiliki sedikit faktor resiko, juga orang tua mungkin memeriksakan anaknya lebih sering pada 
bagian Pediatri dibandingkan dengan bagian Kulit dan Kelamin.

\section{SIMPULAN}

Dari penelitian ini kasus kandidiasis kutis cukup sering ditemukan di poliklinik Kulit dan Kelamin yang merupakan 26,27\% dari kasus baru dermatomikosis. Kandidiasis kutis yang paling sering didapatkan ialah kandidiasis intertriginosa. Perempuan lebih sering terkena kandidiasis kutis dibandingkan laki-laki, 45-64 tahun merupakan kelompok umur yang paling banyak menderita kandidiasis kutis dan yang paling sedikit ialah kelompok umur $<1$ tahun.

\section{UCAPAN TERIMA KASIH}

Ditujukan kepada Dr. Marlyn Grace Kapantow, SpKK(K) dan dr. Nurdjanah J. Niode, SpKK selaku penguji I dan penguji II yang telah memberi masukan dan saran dalam penulisan serta kepada semua pihak yang secara langsung maupun tidak langsung telah memberikan ide tau gagasan dalam penulisan ini.

\section{DAFTAR PUSTAKA}

1. Janik MP, Heffernan MP. Yeast infection: candidiasis and tinea (pityriasis) versicolor. Dalam: Wolff $\mathrm{K}$, Goldsmith LA, Katz SI, Gilchrest BA, Paller AS, Leffell DJ, editor. Fitzpatrick's Dermatology in General Medicine (Edisi ke-7). hal. 1822.

2. Scheinfeld NS. Cutaneous candidiasis. 25 Juni 2012 [diakses pada 19 Oktober 2012]. Tersedia dari http://emedicine.medscape.com/article/109 0632-overview\#showall

3. Rarasati PN. Kesesuaian pemeriksaan laboratorium antara lesi utama dan lesi satelit pada penderita kandidosis kutis [Skripsi]. Semarang: Fakultas Kedokteran Universitas Diponegoro; 2008.

4. Adiguna MS. Epidemiologi dermatomikosis di indonesia. Dalam: Budimulja U, Kuswadji, Bramono K, Menaldi SL, Dwihastuti P, Widaty S, editor. Dermatomikosis Superfisialis (Edisi ke-2). Jakarta: Balai Penerbit FKUI, 2004; p.1-6.

5. Kothavade RJ, Kura MM, Valand AG, Panthaki MH. Candida tropicalis: its prevalence, pathogenicity and increasing resistance to fluconazole. J Med Microbiol. 201059:873-80.

6. Ramali LM. Kandidiasis kutan dan mukokutan. Dalam: Budimulja U, Kuswadji, Bramono K, Menaldi SL, Dwihastuti P, Widaty S, editor. Dermatomikosis superfisialis (Edisi ke-2). Jakarta: Balai Penerbit FKUI, 2004; p.5874.

7. Berhimpon AM. Profil kandidosis pada penderita yang bekunjung ke Poliklinik Kulit dan Kelamin di RSUP Manado periode Januari 1999-Desember 2001 [Skripsi]. Manado: Fakultas Kedokteran Sam Ratulangi; 2003.

8. Citrashanty I, Suyoso S. Mikosis superfisialis di Divisi Mikologi Unit Rawat Jalan Kulit dan Kelamin RSUD dr Soetomo Surabaya periode tahun 2008-2010. Berkala ilmu kesehatan kulit dan kelamin. 2011;23:200-206.

9. Nawal P, Patel S, Patel M, Soni S, Khandelwal N. A study of superficial mycoses in tertiary care hospital. Natl J Integrated Res Med. 2012;3(1):90-93.

10. Havlickova B, Czaika VA, Friedrich $M$. Epidemiological trends in skin mycoses worldwide. Mycoses. 2008;51:2-15.

11. Adiguna MS. Update treatment in inguinal intertrigo and its deffential diagnosis. PERDOSKI. P2KB Dermstoses \& STI Associated With Travel To Tropical Country; 22-23 Okt 2011; Surabaya. 2011. hal 309-33.

12. Jayatilake JAMS, Tilakaratne WM, Panagoda GJ. Candidal onychomycosis: a mini review. Mycopathologia. 2009;168:165-73.

13. Perkumpulan endokrinologi Indonesia. Konsensus pengelolaan dan pencegahan diabetes mellitus tipe 2 di Indonesia 2011. Jakarta: PB PERKENI; 2011. 